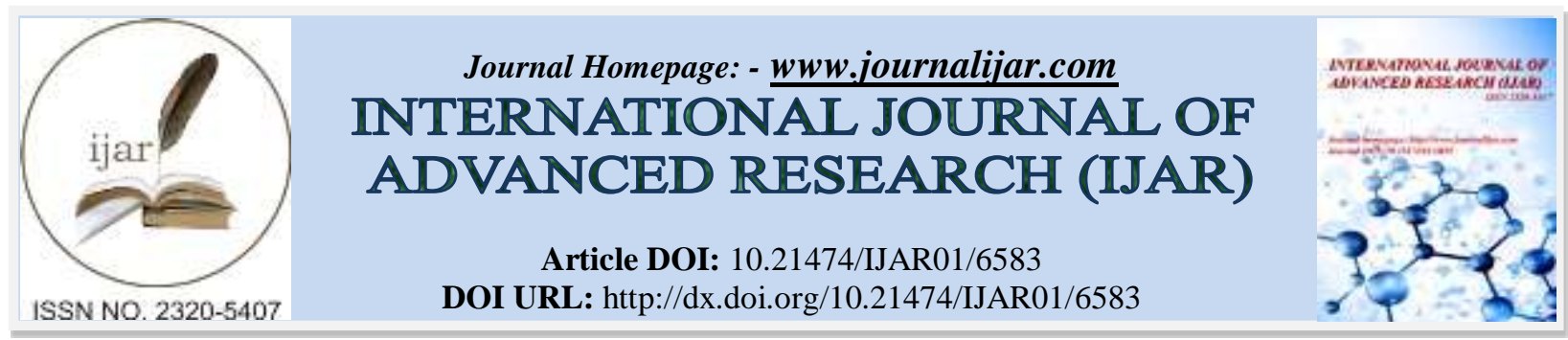

RESEARCH ARTICLE

\title{
AWARENESS, PERCEPTIONS AND KNOWLEDGE OF AMBLYOPIA AMONG PEDIATRICS AND OPHTHALMOLOGY CLINICS ATTENDEES IN KING ABDULAZIZ UNIVERSITY HOSPITAL, JEDDAH.
}

\author{
Nujood Alzahrani ${ }^{1}$, Nizar Alhibshi ${ }^{2}$, Dania Bukhari ${ }^{1}$, Maram Aljohani ${ }^{1}$ and Firas Madani ${ }^{2}$. \\ 1. Faculty of Medicine, King Abdulaaziz University, Jeddah, Saudi Arabia. \\ 2. Ophthalmology Department, King Abdulaziz University Hospital, Jeddah, Saudi Arabia.
}

\section{Manuscript Info}

\section{Manuscript History}

Received: 19 December 2017

Final Accepted: 21 January 2018

Published: February 2018

Key words:-

Amblyopia, awareness, knowledge, pediatric, Saudi Arabia.

\begin{abstract}
Objectives: To assess the knowledge, awareness, and perception about amblyopia and related disease dimensions among the parents and companions of children attending the pediatrics and ophthalmology clinic.

Methodology: A prospective cross-sectional study was conducted using a semi-structured questionnaire including the companions of children who attended the Pediatrics and Ophthalmology clinics at King Abdulaziz University Hospital, Jeddah, Saudi Arabia.

Results: The total number of the participants was 474 with an amblyopia awareness rate of $49.7 \%$. Only $41.0 \%$ and $33.9 \%$ correctly identified amblyopia definition as being a vision loss in one eye or decreased vision in one or both eye, respectively. Additionally, refractive errors, strabismus, and cataract were appropriately perceived as disease etiologies among $54.5 \%, 46.1 \%$, and $28.9 \%$ of the participants, respectively. Knowledge about treatment options showed that $18.8 \%$ of the participants identified patching the strong eye, while using glasses was perceived by $47.6 \%$. Approximately half of the respondents agreed that amblyopia may cause severe complications. knowledge level was significantly increased among females than males $(\mathrm{p}=0.037)$, among parents versus other relatives $(\mathrm{p}=0.009)$, and among those having a positive family history of amblyopia if compared to their counterparts $(p=0.013)$. Relatives/friends and internet/social media represented the main sources of knowledge for the amblyopia-aware individuals.

Conclusion: The present study revealed low awareness levels about amblyopia with inadequate knowledge about disease causes, treatment options, importance of early detection, and treatment compliance. As such, we suggest conducting public health education programs that regularly keep the parents knowledgeable about the disease, its causes and consequence. Cost-effective modalities should be considered for the screening purposes.
\end{abstract}

Copy Right, IJAR, 2018,. All rights reserved. 


\section{Introduction:-}

Amblyopia can be referred to as a functional vision loss mainly due to abnormal visual development as a result of abnormal visual cortex stimulation without obvious structural or pathological abnormalities of the eye or brain (Wright, 2006). It is the most common cause of vision impairment in children and one of important etiologies of decreased vision during adulthood (Wu \& Hunter, 2006). The most susceptible individuals to amblyopia are children between birth and up to 7 years of age (Keech \& Kutschke, 1995) where the major visual defects occur with earlier onset of abnormal stimulation. Approximately $50 \%$ of amblyopia cases are caused by uncorrected high refractive errors (Attebo et al., 1998), but can be associated with several other conditions that may affect the child's visual development, such as constant unilateral strabismus, anisometropia, unilateral or bilateral astigmatism, and bilateral isoametropia (Ciuffreda et al., 1991). Less common etiologies include congenital cataract and corneal injuries or dystrophy (Hatt et al., 2006).

Amblyopia is a public health problem as it affects 2 to $3 \%$ of children with a slight variation according to the studied population and the employed definition (Lam et al., 1993; Pediatric Eye Disease Investigator Group, 2003; Reese \& Weingeist, 1987; Repka et al., 2004). For example, when amblyopia was defined as a visual acuity less than or equal to 0.63, the overall prevalence ranged from 3 to 5.6\% in Germany. In Saudi Arabia, prevalence varies depending on region, with 3.9\% in Qassim province (Aldebasi, 2015), 2.6\% in Riyadh among preschool children (Al-Assaf \& Fatani, 1994), 1.9\% in Abha (Abolfotouh \& Aheem, 1994), and 1.6\% in AlBaha (Al Faran, 1992) among children in school age. However, the prevalence among children aged 1-15 years was $9.5 \%$ in a recent study in Dammam (Al-Tamimi et al., 2015). Finally, kindergarten children in Jeddah showed a prevalence rate of 1.3\% (Bardisi \& Bin Sadiq, 2002).

Amblyopia may negatively impact school progress, sports activities, and the later job opportunities. Furthermore, some psychological difficulties were reported in amblyopic patients including personal self-image, depression, and anxiety (Al-Yahya et al., 2012). Bilateral visual impairment increases up to two to three folds in patients with unilateral amblyopia than non-amblyopic patients (Elflein et al., 2015). Amblyopia is highly responsive to treatment, but the therapy should be started as early as possible before attaining an advanced visual maturation. Otherwise, chances for therapeutic success are significantly reduced in older children (Flynn et al., 1999; Fronius et al., 2014) with high probability of failure in adult patients (Wu \& Hunter, 2006).

Moreover, compliance to treatment and regular follow-up are essential determinant factors for satisfactory therapeutic outcomes. In addition to the preventive approaches that are crucial to limit the development of amblyopia and subsequent life-long visual impairment, the basic tasks of ophthalmologists should be targeted at detecting the manifesting disorder at a treatable stage. Therefore, it appears important for the parents to have a sufficient level of awareness and knowledge about disease symptoms to present their child to the specialists as early as possible in order to improve the outcomes and follow-up.

Up to our knowledge, few Saudi studies were conducted to assess the awareness and attitudes to common eye diseases, including amblyopia, among the patients and their parents. However, no identified studies concerned exclusively with the general perception regarding the amblyopia. We conducted this study to provide an outline of peoples' perception to the causes, diagnosis, consequences, and treatment of amblyopia in Saudi Arabia. As such, we emphasize the role of parents in obtaining the best outcomes through early detection as well as compliance with treatment and providing the adequate support. The associated demographic factors were also demonstrated to detect the most significant conditions. Subsequently, relevant awareness programs could be conducted to the most deficient aspects.

\section{Methods:-}

Population and setting

This was the second of a two-part study on awareness and knowledge about strabismus and amblyopia. A prospective cross-sectional study carried out between 01 January and 31 July 2017 at King Abdulaziz University hospital (KAUH), Jeddah, Saudi Arabia. The study included male and female adult (age>18 years) companions of children (aged $<14$ years) attending the Pediatrics and Ophthalmology outpatient clinics for follow up of ophthalmologic or other health conditions. 


\section{Sampling}

Previous studies reported very poor awareness about amblyopia, namely $2.9 \%$ in Nigeria (Ebeigbe \& Emedike, 2017) and 4.0\% in India (Senthilkumar et al., 2013). Using these rates as reference value resulted in target sample size $=60$. Thus, considering both studies; strabismus and amblyopia, sample size $(\mathrm{N}=289)$ was calculated to detect $75 \%$ of awareness level about strabismus (the primary objective of the twin study) (Isawumi et al., 2014), with 95\% confidence interval, $80 \%$ statistical power and 0.05 type I error. Sample size was rounded to 300, then increased by $50 \%$ to adjust for eventual drop outs and missing data, resulting in a final sample size $=450$. Participants were recruited from the participating clinics using a convenience sampling method.

Study tool

A semi-structured questionnaire was developed by author for the purpose of the study including 6 parts: 1) demographic and socioeconomic data of the participants such as age, gender, relation to child (parent, sibling, grandparent, other), household monthly income, family history of eye disease, etc.; 2) awareness about amblyopia (1 item) and perception about its diagnosis and detection (3 items); 3) knowledge about amblyopia with regards to 3 dimensions including definition (10 items), possible etiologies (14 items), and treatment options (6 items); 4) perception about possible consequences and impact of amblyopia including visual, psychosocial and economic aspects (10 items), using a 4-point Likert-type agreement scale; 5) perception about parents' role in prevention, early detection, diagnosis, treatment efficacy, compliance with treatment, follow-up, psychological and social supports of the afflicted child, using a 5-point Likert-type scale ( $1=$ not important at all to $5=$ very important); 6) sources of knowledge (internet and social media, doctor, relatives and friends, etc.).

The questionnaire was reviewed by one ophthalmologist and underwent face and content validity. Verbal consent was taken from participants prior to interview. Both the study protocol and questionnaire were approved by the institutional review board of KAUH.

Statistical methods

Statistical analysis was performed with the Statistical Package for Social Sciences version 21.0 for Windows (SPSS Inc., Chicago, IL, USA). Descriptive statistics were used to present participants' characteristics as well as the pattern of answers to the different questionnaire parts. Categorical variables are presented as frequency and percentage, while continuous variables are presented as mean \pm standard deviation (SD). Amblyopia knowledge score (AKS, theoretical range 0-30) was calculated as the number of correct answers for questions relating to definition (10 items), etiology (14 items) and treatment options (6 items) of amblyopia. Normality testing of AKS was carried out in the study population using Kolmogorov-Smirnov statistics $=0.085(\mathrm{p}<0.001)$ and Shapiro-Wilk statistics $=0.983$ $(\mathrm{p}=0.006)$, concluding to non-normal distribution of the variable. Consequently, nonparametric tests including Mann-Whitney U and Kruskal-Wallis tests were used to analyze factors of amblyopia knowledge; results are presented as mean AKS with significance level. A p value of $<0.05$ was considered to reject the null hypothesis.

\section{Results:-}

Questionnaire reliability

Internal consistency of the knowledge-related subscales of the questionnaire showed Cronbach's alpha=0.661 (30 items). Internal consistency of other subscales showed Cronbach's alpha $=0.975$ for perception about amblyopia complications (10 items), 0.920 for perceived parent's role in strabismus management ( 8 items).

Population's characteristics

The study included 474 companions of children attending the Pediatrics (74.9\%) and Ophthalmology (25.1\%) departments, mean (SD) age=34.89 (9.75), 69.8\% were females, 85.4\% married and 94.9\% living in urban area. Of the companions, $72.4 \%$ were parents, $12.0 \%$ siblings and $2.5 \%$ grandparents of the patients. Other sociodemographic characteristics showed that $37.3 \%$ had low economic status, $42.8 \%$ were unemployed, and majority $(54.2 \%)$ had high educational level. Family history showed $32.9 \%$ of eye diseases (Table 1).

Table 1:- Participant's characteristics $(\mathrm{N}=474)$

\begin{tabular}{|l|l|l|l|}
\hline Parameter & Category & Frequency & Percentage \\
\hline \multirow{2}{*}{ Clinic } & Pediatrics & 355 & 74.9 \\
\cline { 2 - 4 } & Ophthalmology & 119 & 25.1 \\
\hline Age (years) & Mean, SD (range=15; 82) & 34.89 & 9.75 \\
\hline
\end{tabular}




\begin{tabular}{|c|c|c|c|}
\hline \multirow{2}{*}{ Gender } & Male & 143 & 30.2 \\
\hline & Female & 331 & 69.8 \\
\hline \multirow[t]{4}{*}{ Marital status } & Single & 28 & 9.8 \\
\hline & Married & 245 & 85.4 \\
\hline & Divorced & 6 & 2.1 \\
\hline & Widow & 4 & 1.4 \\
\hline \multirow[t]{2}{*}{ Nationality } & Saudi & 311 & 65.6 \\
\hline & Non-Saudi & 158 & 33.3 \\
\hline \multirow[t]{2}{*}{ Residency } & Urban & 450 & 94.9 \\
\hline & Rural & 19 & 4.0 \\
\hline \multirow[t]{4}{*}{ Monthly income (SAR) } & $<5,000$ & 177 & 37.3 \\
\hline & $5,000-10,000$ & 148 & 31.2 \\
\hline & $10,000-15,000$ & 102 & 21.5 \\
\hline & $>15,000$ & 36 & 7.6 \\
\hline \multirow[t]{4}{*}{ Occupation } & Employed & 203 & 42.8 \\
\hline & Housewife & 215 & 45.4 \\
\hline & Unemployed & 41 & 8.6 \\
\hline & Retired & 13 & 2.7 \\
\hline \multirow[t]{4}{*}{ Educational level } & Illiterate & 16 & 3.4 \\
\hline & Up to middle school & 70 & 14.8 \\
\hline & Secondary & 129 & 27.2 \\
\hline & University or above & 257 & 54.2 \\
\hline \multirow[t]{4}{*}{ Number of children } & None & 37 & 7.8 \\
\hline & $1-2$ & 145 & 30.6 \\
\hline & $3-5$ & 186 & 39.2 \\
\hline & $>5$ & 69 & 14.6 \\
\hline Age of youngest child (years) & $\begin{array}{l}\text { Median, 75th centile (range }=0 \text {; } \\
\text { 27) }\end{array}$ & 3.00 & 5.00 \\
\hline \multirow[t]{4}{*}{ Relation to child } & Parent & 343 & 72.4 \\
\hline & Sibling & 57 & 12.0 \\
\hline & Grandparent & 12 & 2.5 \\
\hline & Other & 45 & 9.5 \\
\hline \multirow[t]{2}{*}{ Family history of eye disease } & No & 313 & 66.2 \\
\hline & Yes & 157 & 32.9 \\
\hline
\end{tabular}

Values are frequency (percentage) unless indicated otherwise; SD: standard deviation; because of missing data some values do not sum up to the total.

Awareness and perception about amblyopia and its diagnosis

Of the total participants, $50.3 \%$ declared being unware of what amblyopia is (awareness rate $=49.7 \%$ ). Of the participants who were aware of amblyopia, 36.2\% believed amblyopia can be detected by naked eye, $40.9 \%$ believed it can be diagnosed by a GP of family doctor, $60.1 \%$ that it can only be diagnosed by an eye specialist and $49.8 \%$ that it can be detected by parents. Further, only $41.7 \%$ are aware that it may occur both in childhood and adulthood (Table 2).

Table 2:- Awareness and perception about amblyopia and its diagnosis

\begin{tabular}{|c|c|c|c|}
\hline Parameter & Category & Frequency & Percentage \\
\hline \multirow{3}{*}{ Awareness about amblyopia } & Yes & 196 & 41.4 \\
\hline & No & 238 & 50.3 \\
\hline & Not sure & 39 & 8.2 \\
\hline \multirow{3}{*}{$\begin{array}{l}\text { Amblyopia can be detected by } \\
\text { naked eye }\end{array}$} & False & 73 & 31.1 \\
\hline & True & 85 & 36.2 \\
\hline & I dont know & 59 & 25.1 \\
\hline \multirow{2}{*}{$\begin{array}{l}\text { Amblyopia can be diagnosed by GP } \\
\text { or family doctor }\end{array}$} & False & 70 & 29.8 \\
\hline & True & 96 & 40.9 \\
\hline
\end{tabular}




\begin{tabular}{|l|l|l|l|}
\hline & I dont know & 53 & 22.6 \\
\hline \multirow{2}{*}{$\begin{array}{l}\text { Amblyopia can only be diagnosed } \\
\text { by eye specialist }\end{array}$} & False & 48 & 20.4 \\
\cline { 2 - 4 } & True & 141 & 60.1 \\
\cline { 2 - 4 } & I dont know & 36 & 15.3 \\
\hline \multirow{2}{*}{$\begin{array}{l}\text { Amblyopia diagnosis requires } \\
\text { specific investigations }\end{array}$} & False & 14 & 6.0 \\
\cline { 2 - 4 } & True & 151 & 64.3 \\
\cline { 2 - 4 } & I dont know & 54 & 23.0 \\
\hline \multirow{2}{*}{$\begin{array}{l}\text { Amblyopia can be detected by } \\
\text { parents }\end{array}$} & No & 49 & 20.9 \\
\cline { 2 - 4 } & yes & 117 & 49.8 \\
\cline { 2 - 4 } & I dont know & 66 & 28.1 \\
\hline Persons exposed to Amblyopia & Adults & 15 & 6.4 \\
\cline { 2 - 4 } & Children & 80 & 34.0 \\
\cline { 2 - 4 } & Both adults and children & 98 & 41.7 \\
\cline { 2 - 4 } & I don't know & 39 \\
\hline
\end{tabular}

Because of missing data some values do not sum up to the total.

Knowledge about amblyopia

Assessment of knowledge was divided into 3 dimensions including definition, etiologies, and treatment option. These were assessed among participants who declared being aware of amblyopia. Results are presented in Figure 1 $(\mathrm{a}, \mathrm{b}, \mathrm{c})$ as the percentage of participants who answered correctly to each item. Knowledge about amblyopia definition showed that only $41.0 \%$ and $33.9 \%$ correctly identified amblyopia as being a vision loss in one eye or decreased vision in one or both eye, respectively; whereas 57.8\% misidentified it as degeneration of optic nerve and $32.3 \%$ as abnormal eye movements. Knowledge about etiologies showed that "refractive errors" was the most frequently identified as an etiology of amblyopia (54.5\%), followed by strabismus (46.1\%), while cataract was only recognized by $28.9 \%$. On the other hand, more than $75 \%$ misidentified exposure to TV and smart devices, heredity, stroke, cerebral palsy, Down syndrome and fever in infancy as etiologies of amblyopia. Knowledge about treatment options showed that $18.8 \%$ only identified patching the strong eye as a systematic curative option for amblyopia and $47.6 \%$ identified glasses as a possible treatment options; whereas $96.2 \%, 89.7 \%$ and $87.4 \%$ misidentified eye muscle exercise, surgery and laser as being part of the amblyopia treatment, respectively.

Figure 1:- Knowledge about amblyopia definition, etiologies, and treatment

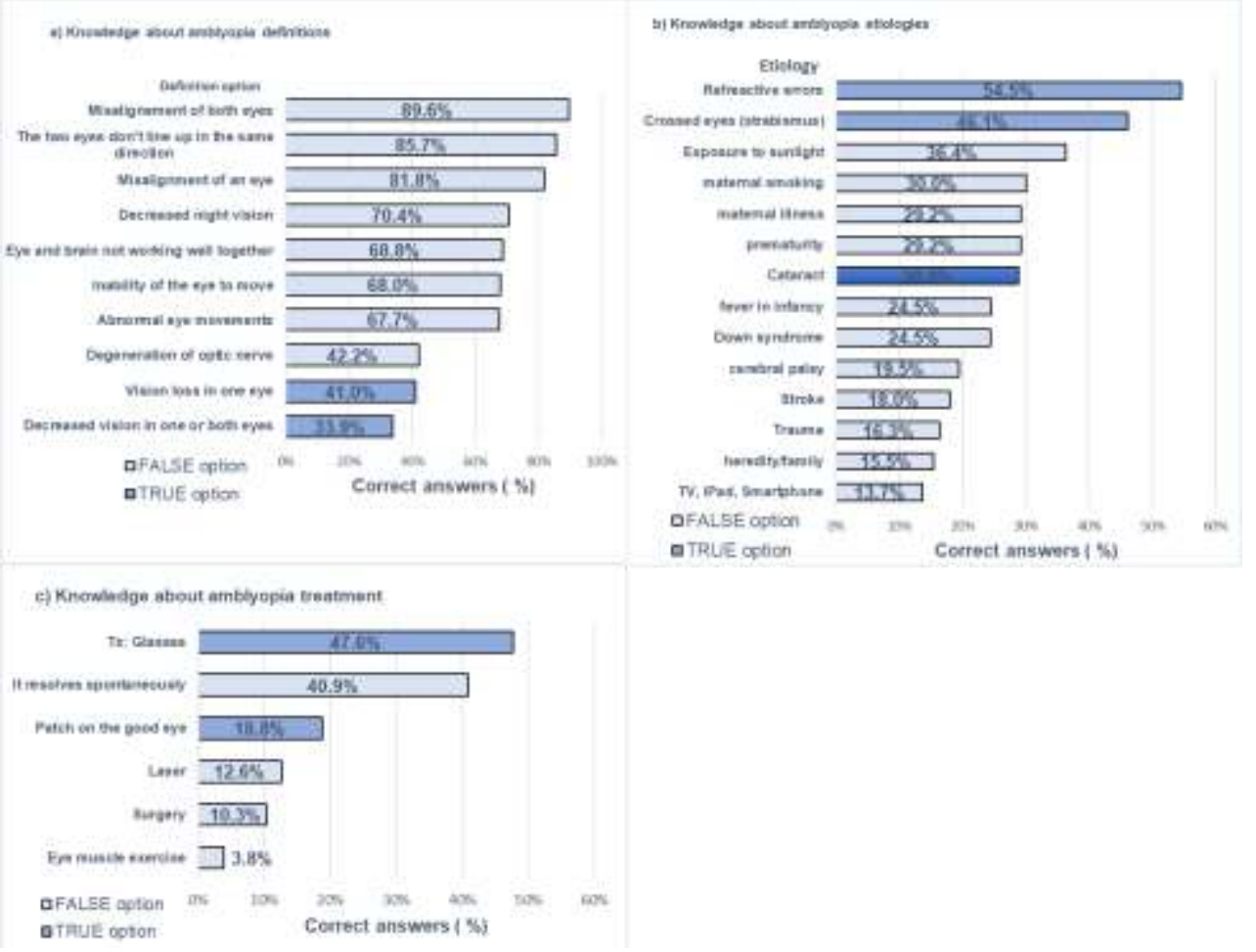


Figure presents knowledge about different dimensions of amblyopia among participants who declared being aware about the conditions ( $\mathrm{N}=235$ ). Knowledge dimensions explored a) definition (10 items, reliability of this part of the corresponding questionnaire scale using Cronbach's alpha= 0.386$)$; b) principal etiologies (14 items, Cronbach's alpha $=0.819)$; and c) treatment options (6 items, Cronbach's alpha $=0.349$ ).

Figure 1:- Sources of knowledge about amblyopia.

Bars represent the percentage of participants who declared having the given item as a source of knowledge about amblyopia.

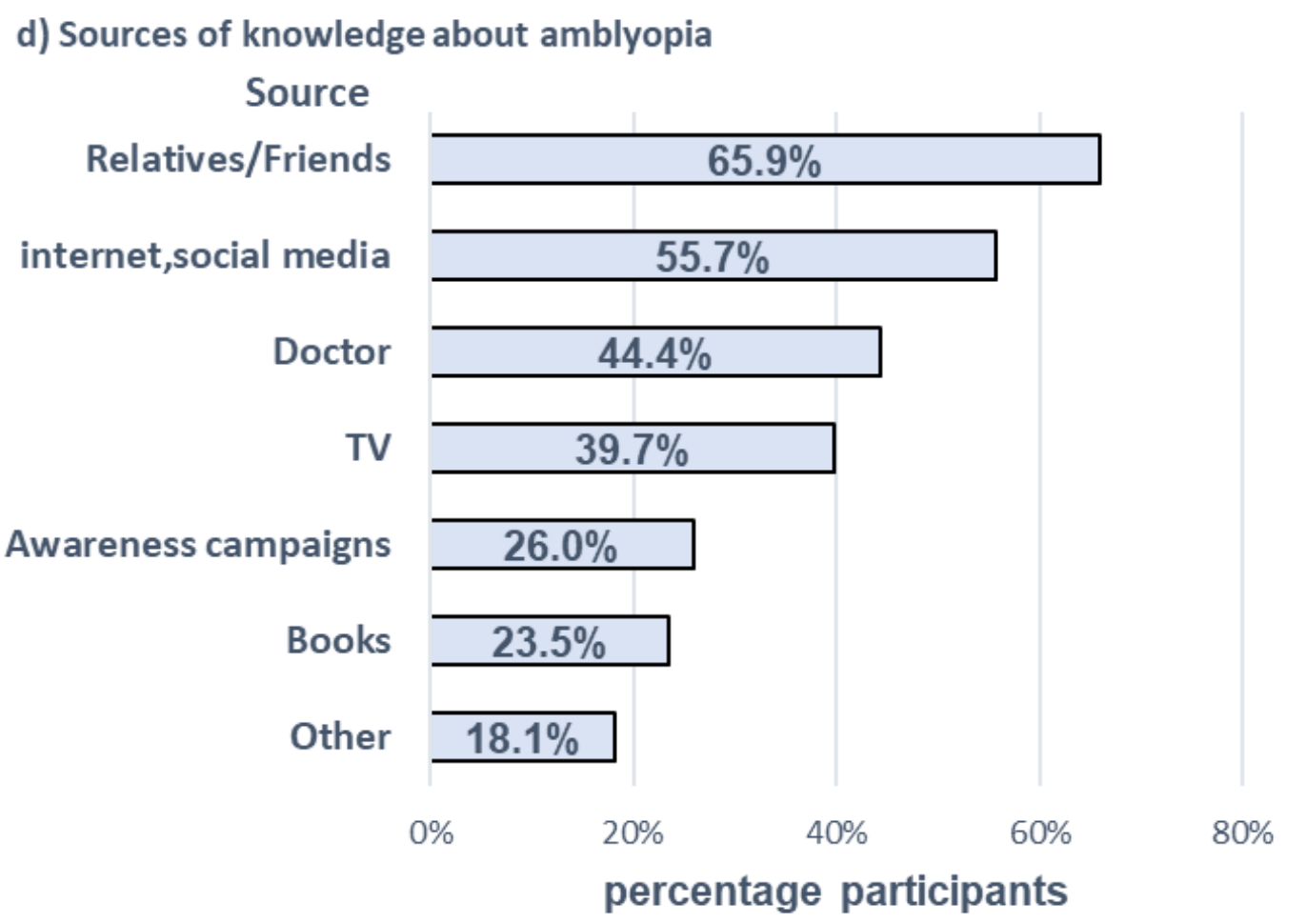

Perceptions about amblyopia complications and treatment outcomes

Majority of participants who declared being aware of amblyopia believed that early treatment leads to better outcomes $(83.8 \%)$, that amblyopia is best treated at young age (84.7\%), and that it worsens if left untreated (79.1\%). Respondents' perception was more divided regarding possible impact and complications of amblyopia, as $40.9 \%$ to $55.7 \%$ of them agreed or strongly agreed that amblyopia may cause vision impairment, disability, stigmatization, impaired quality of life, psychological impact and school failure; whereas only $36.6 \%$ believed it lead to economic burden for the family or society (Table 3 ).

Table 3:- Perception and attitude about amblyopia complications and treatment outcomes

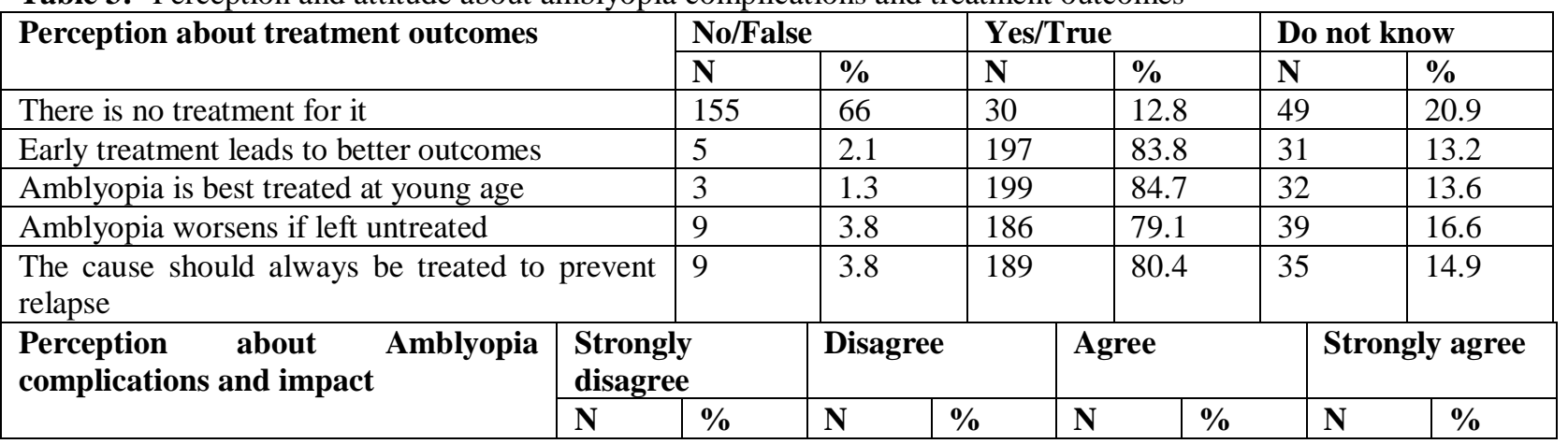




\begin{tabular}{|l|l|l|l|l|l|l|l|l|}
\hline Decreased visual acuity & 7 & 3.0 & 26 & 11.1 & 161 & 68.5 & 35 & 14.9 \\
\hline Double vision & 11 & 4.7 & 99 & 42.1 & 100 & 42.6 & 12 & 5.1 \\
\hline Blindness & 12 & 5.1 & 92 & 39.1 & 103 & 43.8 & 15 & 6.4 \\
\hline Disability & 18 & 7.7 & 111 & 47.2 & 87 & 37.0 & 10 & 4.3 \\
\hline Stigmatization & 13 & 5.5 & 96 & 40.9 & 100 & 42.6 & 20 & 8.5 \\
\hline Impaired quality of life & 12 & 5.1 & 85 & 36.2 & 111 & 47.2 & 20 & 8.5 \\
\hline Negative impact on family & 19 & 8.1 & 103 & 43.8 & 90 & 38.3 & 17 & 7.2 \\
\hline Anxiety, Depression & 22 & 9.4 & 74 & 31.5 & 116 & 49.4 & 16 & 6.8 \\
\hline School failure & 34 & 14.5 & 100 & 42.6 & 89 & 37.9 & 7 & 3.0 \\
\hline Economic burden (family) & 28 & 11.9 & 116 & 49.4 & 73 & 31.1 & 13 & 5.5 \\
\hline
\end{tabular}

Because of missing data some values do not sum up to the total. N: number; \% percentage; percentages are calculated on participants who declared being aware of amblyopia.

Perceived parent's role in amblyopia management

Majority (78.7\% to $90.2 \%$ ) of the participants perceived the parents' role in amblyopia as being important or very important, particularly in the following dimensions: compliance with treatment (90.2\%); diagnosis (88.5\%); follow up $(88.5 \%)$ and early detection $(87.7 \%)$. It is worth noting that approximately $21.3 \%$ would not consider the role of patients in prevention (Table 4).

Table 4:- Perceived parents' role in amblyopia, in different dimensions

\begin{tabular}{|c|c|c|c|c|c|c|c|c|c|c|c|}
\hline \multirow[t]{2}{*}{ Dimension } & \multicolumn{2}{|c|}{$\begin{array}{l}\text { Not } \\
\text { important at } \\
\text { all }\end{array}$} & \multicolumn{2}{|c|}{$\begin{array}{l}\text { Not } \\
\text { important }\end{array}$} & \multicolumn{2}{|c|}{$\begin{array}{l}\text { Somewhat } \\
\text { important }\end{array}$} & \multicolumn{2}{|c|}{ Important } & \multicolumn{2}{|c|}{$\begin{array}{l}\text { Very } \\
\text { important }\end{array}$} & \multirow{2}{*}{$\begin{array}{l}\mathbf{A} \\
\%\end{array}$} \\
\hline & $\mathbf{N}$ & $\%$ & $\mathbf{N}$ & $\%$ & $\mathbf{N}$ & $\%$ & $\mathbf{N}$ & $\%$ & $\mathbf{N}$ & $\%$ & \\
\hline Prevention & 8 & 3.4 & 9 & 3.8 & 28 & 11.9 & 79 & 33.6 & 106 & 45.1 & $\mathbf{7 8 . 7}$ \\
\hline Early detection & 4 & 1.7 & 3 & 1.3 & 17 & 7.2 & 81 & 34.5 & 125 & 53.2 & 87.7 \\
\hline Diagnosis & 4 & 1.7 & 5 & 2.1 & 13 & 5.5 & 82 & 34.9 & 126 & 53.6 & 88.5 \\
\hline $\begin{array}{l}\text { Treatment } \\
\text { efficacy }\end{array}$ & 2 & 0.9 & 5 & 2.1 & 19 & 8.1 & 88 & 37.4 & 116 & 49.4 & 86.8 \\
\hline $\begin{array}{l}\text { Compliance with } \\
\text { treatment }\end{array}$ & 1 & 0.4 & 2 & 0.9 & 15 & 6.4 & 72 & 30.6 & 140 & 59.6 & 90.2 \\
\hline Follow up & 0 & 0 & 2 & 0.9 & 20 & 8.5 & 78 & 33.2 & 130 & 55.3 & 88.5 \\
\hline Social support & 6 & 2.6 & 11 & 4.7 & 12 & 5.1 & 76 & 32.3 & 125 & 53.2 & 85.5 \\
\hline $\begin{array}{l}\text { Psychological } \\
\text { support }\end{array}$ & 5 & 2.1 & 11 & 4.7 & 18 & 7.7 & 83 & 35.3 & 113 & 48.1 & 83.4 \\
\hline
\end{tabular}

A: important or very important (percentage);

Factors associated with knowledge about amblyopia

Based on AKS, knowledge level was statistically associated with gender as it was higher among females versus males (mean $\pm \mathrm{SD} \mathrm{AKS}=11.92 \pm 4.18$ versus $10.83 \pm 4.28$; Mann-Whitney $\mathrm{U}$ test, $\mathrm{p}=0.037$ ). It was also higher among parents $(12.30 \pm 4.19)$ versus sibling $(10.24 \pm 3.35)$ and other companions $(10.48 \pm 4.57)$ and the difference was statistically significant (Kruskal-Wallis test, $\mathrm{p}=0.009$ ). Participants having family history of eye disease had better knowledge about amblyopia (mean \pm SD AKS $=12.58 \pm 4.63$ versus $10.97 \pm 3.91$; Mann-Whitney $U$ test, $\mathrm{p}=0.013$ ) by comparison to their counterparts. No statistically significant association with age, $(\mathrm{p}=568$, linear regression), residency area $(\mathrm{p}=0.063)$, economic status $(\mathrm{p}=0.640)$ or educational level $(\mathrm{p}=0.475)$ was observed. Similarly, knowledge source did not influence knowledge level ( $p>0.050)$ (Table 5).

Table 5:- Factors of knowledge about amblyopia

\begin{tabular}{|l|l|l|l|l|}
\hline \multirow{2}{*}{ Parameter } & Category & \multicolumn{2}{|l|}{ Knowledge level (AKS) } & \multirow{2}{*}{ p-value } \\
\cline { 3 - 4 } & & Mean & SD & \\
\hline \multirow{2}{*}{ Clinic } & Pediatrics & 11.20 & 4.07 & .073 \\
\cline { 2 - 4 } & Ophthalmology & 12.41 & 4.52 & \\
\hline Age (years) & B, r) & .017 & .038 & .568 \\
\hline \multirow{2}{*}{ Gender } & Male & 10.83 & 4.28 & $.037^{*}$ \\
\cline { 2 - 4 } & Female & 11.92 & 4.18 & \\
\hline
\end{tabular}




\begin{tabular}{|c|c|c|c|c|}
\hline \multirow[t]{3}{*}{ Marital status } & Single & 10.12 & 3.27 & \multirow[t]{3}{*}{.060} \\
\hline & Married & 11.79 & 4.36 & \\
\hline & Divorced & 12.10 & 3.78 & \\
\hline \multirow[t]{2}{*}{ Nationality } & Saudi & 11.32 & 4.01 & \multirow[t]{2}{*}{.331} \\
\hline & Non-Saudi & 12.11 & 4.86 & \\
\hline \multirow[t]{2}{*}{ Residency } & Urban & 11.69 & 4.22 & \multirow[t]{2}{*}{.063} \\
\hline & Rural & 8.28 & 3.72 & \\
\hline \multirow[t]{4}{*}{ Monthly income (SAR) } & $<5,000$ & 11.91 & 4.21 & \multirow[t]{4}{*}{.640} \\
\hline & $5,000-10,000$ & 12 & 4.10 & \\
\hline & $10,000-15,000$ & 11.71 & 3.77 & \\
\hline & $>15,000$ & 10.58 & 5.13 & \\
\hline \multirow[t]{3}{*}{ Occupation } & Employed & 11.36 & 4.41 & \multirow[t]{3}{*}{.172} \\
\hline & Housewife & 12.07 & 3.99 & \\
\hline & Unemployed & 10.88 & 4.48 & \\
\hline \multirow[t]{3}{*}{ Educational level } & Up to middle school & 11.36 & 3.20 & \multirow[t]{3}{*}{.475} \\
\hline & Secondary & 10.96 & 4.20 & \\
\hline & University or above & 11.77 & 4.37 & \\
\hline \multirow[t]{4}{*}{ Number of children } & None & 10 & 3.16 & \multirow[t]{4}{*}{.221} \\
\hline & $1-2$ & 12.17 & 4.19 & \\
\hline & $3-5$ & 11.68 & 4.15 & \\
\hline & $>5$ & 11.70 & 4.84 & \\
\hline \multirow[t]{3}{*}{ Relation to child } & Parent & 12.30 & 4.19 & \multirow[t]{3}{*}{$.009^{*}$} \\
\hline & Sibling & 10.24 & 3.35 & \\
\hline & Other & 10.48 & 4.57 & \\
\hline \multirow{2}{*}{$\begin{array}{l}\text { Family history of eye } \\
\text { disease }\end{array}$} & No & 10.97 & 3.91 & \multirow[t]{2}{*}{$.013^{*}$} \\
\hline & Yes & 12.58 & 4.63 & \\
\hline \multicolumn{5}{|l|}{ Knowledge source } \\
\hline \multirow[t]{2}{*}{ Internet, social media } & No & 11.70 & 4.40 & \multirow[t]{2}{*}{.837} \\
\hline & Yes & 11.61 & 4.05 & \\
\hline \multirow[t]{2}{*}{ Doctors } & No & 11.49 & 4.12 & \multirow[t]{2}{*}{.660 } \\
\hline & Yes & 11.78 & 4.31 & \\
\hline \multirow[t]{2}{*}{ Relatives / friends } & No & 11.46 & 4.07 & \multirow[t]{2}{*}{.796} \\
\hline & Yes & 11.64 & 4.35 & \\
\hline \multirow[t]{2}{*}{ TV } & No & 11.73 & 4.34 & \multirow[t]{2}{*}{.585} \\
\hline & Yes & 11.53 & 4.04 & \\
\hline Books & No & 11.56 & 4.25 & .520 \\
\hline & Yes & 11.96 & 4.07 & \\
\hline Awareness campaigns & No & 11.61 & 4.26 & .881 \\
\hline & Yes & 11.65 & 4.09 & \\
\hline
\end{tabular}

AKS: Amblyopia knowledge score (range=1-26); * statistically significant result ( $p<0.05)$; test used; Mann-Whitney $U$ test for factors with binomial variables and Kruskal-Wallis test for factors with multinomial variables; B: unstandardized regression coefficient; $r$ : correlation coefficient.

\section{Discussion:-}

Parents play an important role in the compliance of treatment recommended for their child's wellbeing. Amblyopia is one of the conditions that requires family involvement, especially parents, along with the ophthalmologists in the management of amblyopia in order to gain the best outcomes. This study is conducted to reveal the current awareness levels and perceptions regarding amblyopia among attendees of ophthalmology and pediatric clinics at King AbdulAziz University Hospital (KAUH) in Jeddah through a self-interview questionnaire.

In the present study, approximately half of the participants were aware about amblyopia. Of them, only $41 \%$ identified the disease as being a vision loss, and about one-third perceived amblyopia as a decrease in vision in one or both eyes. The majority of parents were unaware about the correct definition of the disease although about $80 \%$ of the participants had at least secondary educational level. However, amblyopia-aware parents correctly perceived 
refractive errors and strabismus as the major etiologies the disease. Indeed, this profile of awareness may significantly contribute to the lack of timely presentation of amblyopic children to the ophthalmologists as well as underestimation of the actual disease prevalence in a given community. Despite the considerable level of parents' awareness about vision-related diseases among children in India, amblyopia was the only condition with poor awareness (Senthilkumar et al., 2013). Only one parent out of 25 who attended Indian focus group discussions was aware about amblyopia as a disease characterized by lazy eyes, reflecting a very low level of awareness in a developing country. Good amblyopia awareness was usually associated with having someone with the disease in the family regardless his/her personal educational level. Similarly, Ebeigbe et al (Ebeigbe \& Emedike, 2017) found that only $2.9 \%$ of the Nigerian parents were aware about amblyopia and this was associated with having a child with the disease. This is consistent with the findings of the present study, where the knowledge about amblyopia was significant among the parents if compared to the same among other children's siblings. In addition, the presence of a family member having an eye disease contributed significantly to good knowledge about amblyopia.

Relatives and friends represented the main source of knowledge about the disease. The role of relatives remains the most significant as per the consistent findings for strabismus (Singh et al., 2017) and other eye diseases (Haddad et al., 2017). Interestingly, internet and social media contributed remarkably in the enrichment of participants' information. Actually, a study depending on knowledge of the ophthalmological disorders and other diseases showed that the patients who received social media-based information about their disease had better clinical outcomes if compared to their control peers (Abogunrin \& Martin, 2013). Using social networks, such as Facebook and Twitter has the potential to increase the levels of communication among the patients and between patients and healthcare professionals, where feedbacks could be exchanged extensively. This could enhance the patients' decision making in regard to treatment options and, on the other hand, the professionals would have better ways to monitor the progress of specific treatments (Masic et al., 2012). Finally, doctors have an important role through providing either face-to-face instructions during follow-up visits or through the internet to reach as many targeted patients as possible without time or place limitations.

The most identified complication of amblyopia was the decrease in visual acuity, disability, stigmatization, and impaired quality of life. Untreated amblyopia has negative effects that lead to disabling bilateral visual impairment (van Leeuwen et al., 2007). Furthermore, unilateral amblyopia has deteriorative impacts on patients' quality of life (Nilsson, 2007). Therefore, one of the basic responsibilities of eye care specialists is the screening of amblyopia in children, particularly those at preschool ages, for early detection of the disease. This can be achieved by specificallydesigned screening tests which can be regarded as suitable alternatives to comprehensive eye examinations performed in preverbal children (Vision in Preschoolers Study Group, 2004). Office-based acuity testing and the use of screening devices, such as photoscreeners and autorefractors, represent the major available screening approaches. However, the problem of finding a cost-effective approach which has high specificity has been emerged (Konig \& Barry, 2004). This is because several reports showed that even highly-sensitive and highly-specific amblyopia screening tests may have high costs if they were applied for screening of large preliterate children populations (Wu \& Hunter, 2006).

Early treatment of amblyopia is crucial, as most of amblyopia types are treatable until the age of 5 years (Haase, 1986). Therefore, early detection of amblyopia is crucial. Parents should have the required knowledge about the disease and how to identify it to subsequently approach healthcare provider upon observing any abnormality. Amblyopia treatment involves eye glasses, patching of the healthy eye, or a combination of both. Atropine eye drops can also be used as an alternative to patching (Repka, 2007) by preventing the treated eye from conditional accommodation and allowing the amblyopic eye to be functional preferentially. Being the cornerstone of amblyopia therapy, it has been shown that successful patching treatment depends mainly on the number of patching hours (Loudon et al., 2002). Children usually show significant improvement in visual acuity with compliance to patching treatment even in those children older than 8 years old (Oliver et al., 1986). However, there is a wide range of variation in the compliance rates among different studies due to physical, social, visual, and psychological aspects (Loudon et al., 2002; Smith et al., 1995; Woodruff et al., 1994). Compliance is better demonstrated in children younger than 4 years old (Loudon et al., 2006), those using lower patching dosage (for example 6-hours regimens) (Stewart et al., 2007), and parents with higher economic status (Loudon et al., 2006). Lack of knowledge about amblyopia and its treatment contributed significantly to non-compliance (Choong et al., 2004; Loudon et al., 2009). In addition, some parent's beliefs, such as their beliefs that they are unable to perform the recommended patching and that the treatment may be of low efficacy, are associated with poor compliance to amblyopia treatment in their children (Loudon et al., 2009). Regarding eye patch materials, the physical properties of the patch (heat, irritation, 
poor adhesion) may cause some sort of discomfort and may affect compliance rates (Roefs et al., 2012). For atropine penalization, parents' concerns about atropine toxicity and sensitivity in some children may represent the major hindering factors to therapeutic compliance (Wang, 2015). Furthermore, many healthcare providers have shown some concerns regarding the side effects and therapeutic efficacy of atropine (Newsham, 2010).

Importantly, the relationship between healthcare provider and the parents is a major determinant factor in treatment compliance, since the compliance rates were higher in parents receiving written information, frequent phone contact and frequent follow-up visits than their poor contacting peers (Loudon et al., 2009; Newsham, 2010; Tjiam et al., 2010). At this point, the importance of internet communication should be emphasized. Physicians should have their knowledge of amblyopia updated regularly. Social support strategies showed promising compliance outcomes. This could be performed by the teachers (for instance, by using entertaining fiction books and novels which facilitate the perception of patching therapy), neighbors, and friends improves compliance in a significant manner (Tjiam et al., 2011).

Compliance to treatment was the most perceived dimension among the participants of this study, where $90.2 \%$ of them considered therapeutic compliance as either important or very important. Although the mean compliance rate to amblyopia patching was $66.68 \%$ in an earlier study conducted at our medical institution (Al-Yahya et al., 2012), the most frequent causes of non-compliance were social stigma, child refusal, and experiencing irritation and heat feeling. Given that the social support and parents' knowledge are not as effective factors as parents' attitudes toward patching therapy, educating parents is not solely sufficient to ensure optimal compliance (Al-Yahya et al., 2012).

The findings of the presents study emphasize an urgent need to the establishment of fundamental guidelines provided to the parents of children having amblyopia to promote the basic education about the disease. For example, this could be attained by distributing awareness brochures at the ophthalmology and pediatric clinics at KAUH. In addition, regular companions on amblyopia and other visual problems in general should be held, focusing on the importance of early detection and access to managemental approaches once the disease has been detected. Amblyopia screening should be carried out in a feasible cost-effective way at our clinics, nearby schools, and shopping malls. Awareness through the internet should also be considered as a novel approach to enrich the ophthalmological knowledge through social media networks and mobile applications.

\section{Conclusion:-}

Amblyopia is considered a significant disabling health problem which can lead to several vision-related complications. It is highly responsive to treatment if the therapy is approached at young ages with good compliance patterns. Parents' awareness and knowledge about the disease plays a vital role in treatment process. The present study showed low awareness levels among the participants regarding amblyopia and its complications. They had also inadequate knowledge about disease causes and treatment options with a lack of perception about the importance of early detection, regular follow-up, and treatment compliance. As such, we suggest conducting public enlightenment and health education programs that regularly keep the parents knowledgeable about the disease, its causes and consequence if left untreated. Doctor-patient relationship should be appreciated in such tailored programs. Finally, it is important to establish cost-effective screening modalities for early detection as well as handling the significant factors that may render poor compliance to treatment. 


\section{References:-}

1. Abogunrin, S., \& Martin, A. (2013): Can the Use of Social Media and Mobile Apps Improve Patient Knowledge of Disease and Health Outcomes? A Systematic Review. Value Health, 16(7): A326.

2. Abolfotouh, M., \& Aheem, Y. (1994): Ocular disorders Among school boys in a high altitude area of Saudi Arabia. Saudi J Ophthalmol, 8: 20-24.

3. Al-Assaf, A., \& Fatani, R. (1994): Vision screening of preschool children in Riyadh. Saudi J Ophthalmol, 8: 914.

4. Al-Tamimi, E. R., Shakeel, A., Yassin, S. A., Ali, S. I., \& Khan, U. A. (2015): A clinic-based study of refractive errors, strabismus, and amblyopia in pediatric age-group. J. Family Community Med., $22(3)$ : 158.

5. Al-Yahya, A., Al-Odan, K., Allam, K., Al-Onazi, B., Mousa, A., \& Al-Saleh, A. A. (2012): Compliance to patching in the treatment of amblyopia. Saudi J Ophthalmol, 26(3): 305-307.

6. Al Faran, M. (1992): Prevalence of ocular disorders among schoolboys in five villages in Al-Baha region. Ann. Saudi Med., 12(1): 3-7.

7. Aldebasi, Y. H. (2015): Prevalence of amblyopia in primary school children in Qassim province, Kingdom of Saudi Arabia. Middle East Afr J Ophthalmol, 22(1): 86.

8. Attebo, K., Mitchell, P., Cumming, R., Smith, W., Jolly, N., \& Sparkes, R. (1998): Prevalence and causes of amblyopia in an adult population. Ophthalmology, 105(1): 154-159.

9. Bardisi, W. M., \& Bin Sadiq, B. M. (2002): Vision screening of preschool children in Jeddah, Saudi Arabia. Saudi Med. J., 23(4): 445-449.

10. Choong, Y., Lukman, H., Martin, S., \& Laws, D. (2004): Childhood amblyopia treatment: psychosocial implications for patients and primary carers. Eye, 18(4): 369.

11. Ciuffreda, K. J., Levi, D. M., \& Selenow, A. (1991). Amblyopia: Basic and clinical aspects (1st ed.). Boston: Butterworth-Heinemann.

12. Ebeigbe, J. A., \& Emedike, C. M. (2017): Parents' awareness and perception of children's eye diseases in Nigeria. J Optom, 10(2): 104-110.

13. Elflein, H. M., Fresenius, S., Lamparter, J., Pitz, S., Pfeiffer, N., Binder, H., . . . Mirshahi, A. (2015): The prevalence of amblyopia in Germany: data from the prospective, population-based Gutenberg Health Study. Dtsch Arztebl Int, 112(19): 338.

14. Flynn, J. T., Woodruff, G., Thompson, J. R., Hiscox, F., Feuer, W., Schiffman, J., . .. Smith, L. K. (1999): The therapy of amblyopia: an analysis comparing the results of amblyopia therapy utilizing two pooled data sets. Trans. Am. Ophthalmol. Soc., 97: 373-390; discussion 390-375.

15. Fronius, M., Cirina, L., Ackermann, H., Kohnen, T., \& Diehl, C. M. (2014): Efficiency of electronically monitored amblyopia treatment between 5 and 16 years of age: new insight into declining susceptibility of the visual system. Vision Res., 103: 11-19.

16. Haase, W. (1986). Amblyopie. In H. Kaufmann (Ed.), Strabismus (pp. 202-279). Stuttgart, Germany: EnkeVerlag.

17. Haddad, M. F., Bakkar, M. M., \& Abdo, N. (2017): Public awareness of common eye diseases in Jordan. BMC Ophthalmol., 17(1): 177.

18. Hatt, S., Antonio-Santos, A., Powell, C., \& Vedula, S. S. (2006): Interventions for stimulus deprivation amblyopia. Cochrane Database Syst Rev(3): Cd005136.

19. Isawumi, M. A., Ulaikere, M., Adejumo, O. O., Adebayo, M., \& Kekunnaya, R. (2014): Awareness, perceptions and knowledge of strabismus among patients visiting a tertiary eye clinic in Southwest Nigeria. Int. Ophthalmol., 34(5): 1037-1042.

20. Keech, R. V., \& Kutschke, P. J. (1995): Upper age limit for the development of amblyopia. J. Pediatr. Ophthalmol. Strabismus, 32(2): 89-93.

21. Konig, H. H., \& Barry, J. C. (2004): Cost-utility analysis of orthoptic screening in kindergarten: a Markov model based on data from Germany. Pediatrics, 113(2): e95-108.

22. Lam, G. C., Repka, M. X., \& Guyton, D. L. (1993): Timing of amblyopia therapy relative to strabismus surgery. Ophthalmology, 100(12): 1751-1756.

23. Loudon, S., Fronius, M., Looman, C. W., Awan, M., Simonsz, B., van der Maas, P. J., \& Simonsz, H. J. (2006): Predictors and a remedy for noncompliance with amblyopia therapy in children measured with the occlusion dose monitor. Invest. Ophthalmol. Vis. Sci., 47(10): 4393-4400.

24. Loudon, S., Passchier, J., Chaker, L., De Vos, S., Fronius, M., Harrad, R., . . . Simonsz, H. (2009): Psychological causes of non-compliance with electronically monitored occlusion therapy for amblyopia. Br. J. Ophthalmol., 93(11): 1499-1503. 
25. Loudon, S., Polling, J. R., \& Simonsz, H. (2002): A preliminary report about the relation between visual acuity increase and compliance in patching therapy for amblyopia. Strabismus, 10(2): 79-82.

26. Masic, I., Sivic, S., Toromanovic, S., Borojevic, T., \& Pandza, H. (2012): Social networks in improvement of health care. Mater Sociomed, 24(1): 48.

27. Newsham, D. (2010): The effect of recent amblyopia research on current practice in the UK. Br. J. Ophthalmol.: bjo. 2009.172015.

28. Nilsson, J. (2007). The negative impact of amblyopia from a population perspective: untreated amblyopia almost doubles the lifetime risk of bilateral visual impairment: BMJ Publishing Group Ltd.

29. Oliver, M., Neumann, R., Chaimovitch, Y., Gotesman, N., \& Shimshoni, M. (1986): Compliance and results of treatment for amblyopia in children more than 8 years old. Am. J. Ophthalmol., 102(3): 340-345.

30. Pediatric Eye Disease Investigator Group. (2003): The course of moderate amblyopia treated with atropine in children: experience of the amblyopia treatment study. Am. J. Ophthalmol., 136(4): 630-639.

31. Reese, P. D., \& Weingeist, T. A. (1987): Pars plana management of ectopia lentis in children. Arch. Ophthalmol., 105(9): 1202-1204.

32. Repka, M. X. (2007): The Pediatric Eye Disease Investigator Group. Am. Orthopt. J., 57(1): 41-47.

33. Repka, M. X., Cotter, S. A., Beck, R. W., Kraker, R. T., Birch, E. E., Everett, D. F., . . Wallace, D. K. (2004): A randomized trial of atropine regimens for treatment of moderate amblyopia in children. Ophthalmology, 111(11): 2076-2085.

34. Roefs, A. M., Tjiam, A. M., Looman, C. W., Simonsz-Toth, B., Fronius, M., Felius, J., . . Loudon, S. (2012): Comfort of wear and material properties of eye patches for amblyopia treatment and the influence on compliance. Strabismus, 20(1): 3-10.

35. Senthilkumar, D., Balasubramaniam, S. M., Kumaran, S. E., \& Ramani, K. K. (2013): Parents' awareness and perception of children's eye diseases in Chennai, India. Optom. Vis. Sci., 90(12): 1462-1466.

36. Singh, A., Rana, V., Patyal, S., Kumar, S., Mishra, S. K., \& Sharma, V. K. (2017): To assess knowledge and attitude of parents toward children suffering from strabismus in Indian subcontinent. Indian J. Ophthalmol., 65(7): 603.

37. Smith, L. K., Thompson, J. R., Woodruff, G., \& Hiscox, F. (1995): Factors affecting treatment compliance in amblyopia. J. Pediatr. Ophthalmol. Strabismus, 32(2): 98-101.

38. Stewart, C. E., Stephens, D. A., Fielder, A. R., \& Moseley, M. J. (2007): Objectively monitored patching regimens for treatment of amblyopia: randomised trial. BMJ, 335(7622): 707.

39. Tjiam, A. M., Akcan, H., Ziylan, F., Vukovic, E., Loudon, S., Looman, C. W., . . Simonsz, H. J. (2011): Sociocultural and psychological determinants in migrants for noncompliance with occlusion therapy for amblyopia. Graefes Arch Clin Exp Ophthalmol, 249(12): 1893-1899.

40. Tjiam, A. M., Vukovic, E., Asjes-Tydeman, W., Holtslag, G., Loudon, S., Sinoo, M., \& Simonsz, H. (2010): How Dutch orthoptists deal with noncompliance with occlusion therapy for amblyopia. Strabismus, 18(4): 146166.

41. van Leeuwen, R., Eijkemans, M. J., Vingerling, J. R., Hofman, A., de Jong, P. T., \& Simonsz, H. J. (2007): Risk of bilateral visual impairment in individuals with amblyopia: the Rotterdam study. Br. J. Ophthalmol., 91(11): 1450-1451.

42. Vision in Preschoolers Study Group. (2004): Comparison of preschool vision screening tests as administered by licensed eye care professionals in the Vision in Preschoolers Study. Ophthalmology, 111(4): 637-650.

43. Wang, J. (2015): Compliance and patching and atropine amblyopia treatments. Vision Res., 114: 31-40.

44. Woodruff, G., Hiscox, F., Thompson, J. R., \& Smith, L. K. (1994): Factors affecting the outcome of children treated for amblyopia. Eye (Lond), 8 ( Pt 6): 627-631.

45. Wright, K. W. (2006). Visual Development and Amblyopia. In K. W. Wright, P. H. Spiegel \& L. S. Thompson (Eds.), Handbook of pediatric strabismus and amblyopia (2nd ed., pp. 103-137). New York: Springer.

46. Wu, C., \& Hunter, D. G. (2006): Amblyopia: diagnostic and therapeutic options. Am. J. Ophthalmol., 141(1): 175-184. 